University of Nebraska - Lincoln

DigitalCommons@University of Nebraska - Lincoln

\title{
A Comparison of Risk Factors for Sexual Victimization Among Gay, Lesbian, Bisexual, and Heterosexual Homeless Young Adults
}

Kimberly A. Tyler

University of Nebraska-Lincoln, kim@ktresearch.net

Follow this and additional works at: https://digitalcommons.unl.edu/sociologyfacpub

Part of the Sociology Commons

Tyler, Kimberly A., "A Comparison of Risk Factors for Sexual Victimization Among Gay, Lesbian, Bisexual, and Heterosexual Homeless Young Adults" (2008). Sociology Department, Faculty Publications. 41.

https://digitalcommons.unl.edu/sociologyfacpub/41

This Article is brought to you for free and open access by the Sociology, Department of at DigitalCommons@University of Nebraska - Lincoln. It has been accepted for inclusion in Sociology Department, Faculty Publications by an authorized administrator of DigitalCommons@University of Nebraska - Lincoln. 


\title{
A Comparison of Risk Factors for Sexual Victimization Among Gay, Lesbian, Bisexual, and Heterosexual Homeless Young Adults
}

\author{
Kimberly A. Tyler, PhD \\ University of Nebraska-Lincoln, Department of Sociology
}

\begin{abstract}
Although high rates of sexual victimization have been reported among homeless youth, less is known about whether the risk factors vary for gay, lesbian, and bisexual youth compared to heterosexual youth. Based on a sample of 172 homeless young adults ages 19 to 26 , results revealed that depressive symptoms, prostitution, and having friends who traded sex were significantly associated with higher levels of sexual victimization. Gay, lesbian, and bisexual young adults experienced more sexual victimization compared to heterosexual young adults. A test for interactions revealed that the effect of sexual orientation on sexual victimization was moderated by trading sex and having friends who traded sex. Finally, there is support for partial mediation of the effects of sexual abuse, neglect, and depressive symptoms on sexual victimization through other risk factors.
\end{abstract}

Keywords: sexual victimization, sexual minority, homeless young adults, maltreatment, trading sex

lthough research has demonstrated that homeless youth in general experience
high rates of victimization on the streets (Baron, 1997; Baron, 2003; Hagan \&
McCarthy, 1997; Tyler, Hoyt, Whitbeck, \& Cauce, 2001b; Whitbeck \& Hoyt,
1999), some research has found that gay, lesbian, and bisexual homeless youth ex-
perience more victimization compared to their heterosexual counterparts because
of their higher rates of sexual and/or physical abuse in the home (Cochran, Stew-
art, Ginzler, \& Cauce, 2002; Rew, Whittaker, Taylor-Seehafer, \& Smith, 2005; Whit-
beck, Chen, Hoyt, Tyler, \& Johnson, 2004), stressors associated with their sexual
orientation (D'Augelli, Hershberger, \& Pilkington, 1998; Martin \& Hetrick, 1988; Pilk-
ington \& D'Augelli, 1995), and bias-related crimes (Herek, Cogan, \& Gillis, 2002; Wil-
lis, 2004). Also, because research finds that gay, lesbian, and bisexual (GLB) youth
are more likely to lack family support (D'Augelli, 1998), have family difficulties, and
run away or be expelled from home (Cochran et al., 2002; Martin \& Hetrick, 1988; Re-
mafedi, 1987; Savin-Williams, 1994), they may be less likely to return home and, con-
sequently, have fewer resources available. As a result, GLB homeless youth may be
more likely to trade sex to support themselves compared to their heterosexual peers
(Kipke, Montgomery, Simon, Unger, \& Johnson, 1997a), and trading sex is linked to
sexual victimization among homeless youth (Tyler, Whitbeck, Hoyt, \& Cauce, 2004; 
Whitbeck \& Hoyt, 1999). As such, sexual minority youth are likely to have higher rates of sexual victimization compared to heterosexual youth.

Even though sexual abuse, risky sexual behavior, and/or deviant peer affiliations are associated with sexual victimization on the street (Tyler, Hoyt, \& Whitbeck, 2000; Tyler, Hoyt, Whitbeck, \& Cauce, 2001a; Whitbeck \& Hoyt, 1999; Whitbeck \& Simons, 1990), less is known about how specific risk factors affect gay, lesbian, and bisexual youth compared to heterosexual youth. As such, the purpose of the current study is to examine the association between early sexual abuse, neglect, depressive symptoms, risky sexual behavior, and friends trading sex with sexual victimization among homeless heterosexual males and females and homeless gay, lesbian, and bisexual young adults.

\section{LITERATURE REVIEW}

\section{Early Abuse and Neglect}

Although child maltreatment is common among homeless youth in general (Tyler \& Cauce, 2002; Tyler et al., 2001a), higher rates of sexual abuse, physical abuse, and/or neglect have been reported among homeless gay, lesbian, and bisexual (GLB) youth compared to their homeless heterosexual counterparts (Cochran et al., 2002; Rew et al., 2005; Whitbeck et al., 2004). Studies of homeless youth have also found higher rates of physical and sexual victimization on the street among GLB youth compared to their heterosexual peers (Cochran et al., 2002; Whitbeck et al., 2004). GLB youth may also experience higher rates of victimization specifically because of their sexual orientation (Hershberger \& D’ Augelli, 1995; Huebner, Rebchook, \& Kegeles, 2004). Incidents such as these are known as hate crimes or bias-related crimes (Herek et al., 2002; Willis, 2004). Also, rates of bias-related crimes among homeless GLB youth may be especially high because many such crimes occur in public settings and are perpetrated by strangers (Herek et al., 2002), exactly the places and people homeless youth are likely to be surrounded by.

Although early maltreatment in the home has been directly linked to later revictimization among homeless youth and adults (cf. Ryan, Kilmer, Cauce, Watanable, \& Hoyt, 2000; Simons \& Whitbeck, 1991; Tyler et al., 2000; Tyler et al., 2001a; Whitbeck, Hoyt, \& Yoder, 1999; Whitbeck \& Simons, 1993), research also finds an indirect effect through high-risk behaviors such as trading sex, prostitution, and associating with deviant peers (Silbert \& Pines, 1982; Simons \& Whitbeck, 1991; Tyler et al., 2001a). High-risk behaviors such as prostitution place youth at particular risk for victimization given that it increases their exposure and the likelihood that they will come into contact with potential offenders (Cohen, Kluegel, \& Land, 1981). In other words, because early maltreatment may lead youth to engage in high-risk behavior on the streets, the lifestyles and daily routines of homeless youth expose them to dangerous people and places, which creates the potential for crime opportunities and increased sexual victimization (Tyler et al., 2001a). As such, the effect of maltreatment on sexual victimization may be both direct and indirect via high-risk behaviors.

\section{Depressive Symptoms}

Research conducted on homeless and runaway youth finds a positive association between depression and victimization (Whitbeck, Hoyt, \& Bao, 2000; Whitbeck et al., 1999). Although homeless youth in general are likely to experience high rates of depression, GLB homeless youth have been found to be significantly more depressed 
compared to their heterosexual counterparts (Cochran et al., 2002; Noell \& Ochs, 2001; Whitbeck et al., 2004). It is also possible that depression acts as a mediator between family abuse and victimization (Ryan et al., 2000; Stiffman, 1989; Whitbeck \& Hoyt, 1999). Abused youth may experience emotional problems such as depression (Morrow \& Sorell, 1989; Tyler, 2002), which in turn may make them more vulnerable to victimization (Ryan et al., 2000; Tyler et al., 2000a). Finkelhor and Browne (1985) state that abused children may experience shame and guilt, suffer from low self-esteem, and may be viewed as "spoiled goods" by others around them (p. 533). This may be particularly salient for GLB youth who in addition to experiencing abuse also face isolation, alienation, and discrimination as a result of their sexual orientation (Cochran et al., 2002; Kruks, 1991; Martin \& Hetrick, 1988). Abused children are likely to feel isolated and depressed and may gravitate toward high-risk activities (Finkelhor \& Browne, 1985) such as trading sex and prostitution, which increase their risk for sexual victimization. As such, the effect of depression on sexual victimization may be direct, as well as indirect via high-risk behaviors.

\section{Risky Sexual Behavior}

Risky sexual practices, including trading sex and prostitution, are quite common among homeless youth. Prostitution, which is typically done exclusively for economic gain (Overall, 1992), can be differentiated from trading sex, which is typically defined as exchanging sex for specific items such as food, shelter, money, or drugs. Homeless youth who engage in these behaviors typically do so out of necessity and for survival purposes. For example, many young people who run away from home find themselves on the streets with little education and few job skills, and are often forced to find a way to support themselves; as a result, some homeless youth have turned to trading sex (Hagan \& McCarthy, 1997; Whitbeck \& Hoyt, 1999). Because sexual minority youth exhibit higher rates of trading sex than heterosexual youth (Clatts \& Davis, 1999; Kipke et al., 1997a; Kipke, O'Connor, Palmer, \& MacKenzie, 1995; Moon et al., 2000; Whitbeck et al., 2004), they are at especially high risk for victimization compared to their heterosexual peers. This higher risk exists because trading sex and prostitution leads to high visibility and puts homeless youth in dangerous and vulnerable situations with little protection from violent customers and others who may try to exploit them (Tyler et al., 2004; Weisberg, 1985). As a result, trading sex and prostitution are likely to increase homeless youths' risk for sexual victimization.

\section{Friends Trading Sex}

Research reveals that many runaways report hanging out with friends as their main activity (Yates, MacKenzie, Pennbridge, \& Cohen, 1988) and that street peers provide guidance and instruction that aid youth in surviving on the street (Kipke, Unger, O'Connor, Palmer, \& LaFrance, 1997b). For example, Kipke and colleagues (1997b) found that affiliation with peers strongly influenced the behavior of homeless youth such that those who associated with hustlers were more likely to rely on prostitution to support themselves financially. If homeless youth spend the majority of their time with other street youth and are strongly influenced by the behaviors of such youth, it is likely that street youth will engage in activities similar to those of their peers. Although having friends who trade sex is positively associated with homeless youth themselves trading sex (Tyler et al., 2000), the causal ordering is unclear because of the cross-sectional nature of the majority of these studies. 


\section{HYPOTHESES}

Based on the review of the literature, a positive association was hypothesized among sexual abuse, neglect, depressive symptoms, risky sexual behavior, and friends trading sex with sexual victimization. It was also expected that risk factors for sexual victimization would vary by sexual orientation because gay, lesbian, and bisexual youth experience higher rates of maltreatment, depressive symptoms, and risky sexual behavior compared to their heterosexual peers (Cochran et al., 2002; Rew et al., 2005; Whitbeck et al., 2004) and because of the stigmatization and discrimination that GLB youth face (D'Augelli, 1998; Kruks, 1991). Therefore, it was hypothesized that the effect of the independent variables on sexual victimization would be moderated by sexual orientation. Finally, based on the literature (Finkelhor \& Browne, 1985; Silbert \& Pines, 1982; Tyler et al., 2001a; Whitbeck \& Hoyt, 1999), it was hypothesized that depressive symptoms, risky sexual behavior, and friends trading sex would mediate the relationship between sexual abuse and neglect on sexual victimization and that risky sexual behavior and friends trading sex would mediate the relationship between depressive symptoms and sexual victimization.

\section{METHOD}

Data for the current study are from the Homeless Young Adult Project (HYAP). Over a period of approximately 1 year, from April 2004 through June 2005, 199 young adults were interviewed in three Midwestern cities. Of this total, 144 were homeless and 55 were currently housed. Participants in the housed sample were obtained via peer nominations from the homeless youth in the study. The reason for the smaller number of housed youth was that the majority of homeless youth had a difficult time nominating housed peers because most of their friends were homeless. Of the 55 currently housed young adults, however, 28 had extensive histories of being homeless and had run away from home numerous times. In fact, the 28 housed young adults who had a history of homelessness had run away more times than the young adults who were currently homeless (mean $=5.72$ vs. 4.99 ), but this difference was not statistically significant. It appears that what differentiated these two groups for the moment was their current housing status, indicating that homelessness is a situation that is fluid, easily changeable, and not easily defined. The final sample included 172 young adults who were currently homeless or who had a history of running away or being homeless.

Interviews were conducted by experienced interviewers who have worked on past projects dealing with at-risk youth, have served for several years in agencies and shelters that support homeless young people, and are familiar with local street cultures such as knowing where to locate youth and where they congregate. All interviewers had also completed the Collaborative Institutional Review Board (IRB) Training Initiative course for the protection of human subjects in research.

Interviewers approached shelter residents and located eligible respondents in areas of the three cities where street youth hang out. Young people were interviewed using a systematic sampling strategy that maximized locating homeless youth. This approach was used, as it is well established that it is not possible to randomly sample homeless populations (Wright, Allen, \& Devine, 1995). Study eligibility required all young people to be between the ages of 19 and 26 and homeless. Interviews were typically conducted in shelter interview rooms, fast food restaurants, or coffee shops. Interviewers obtained informed consent from all young adults before participation in 
the study. Respondents were told about the confidentiality of the study, that their participation was completely voluntary, and that they had the right to refuse to answer any question or end the interview at any time. The interviews lasted approximately 1 hour and all participants received a modest reimbursement for their involvement. Referrals and services (e.g., shelter, counseling services, food services) were offered to the young adults at the time of the interview. Although screening rates were not formally tallied, field interviewers reported that very few young adults refused to participate.

\section{Participants}

The sample included 69 females (40.1\%) and 103 males (59.9\%). Of these, 31 youth $(18.5 \%)$ self-identified as gay, lesbian, or bisexual. The age of the sample ranged from 19 to 26 years, with a mean of 21.45 years. The majority of the sample was White $(80 \%)$, approximately $9 \%$ were Black, and $5 \%$ were biracial or multiracial. The remainder of the sample was composed of 3.5\% Hispanic, 2\% American Indian, and 1\% Asian. In all, $13 \%$ of respondents had a ninth-grade education or less, $9 \%$ completed tenth grade, 15\% completed eleventh grade, and almost 37\% completed high school. Finally, 16\% obtained their general equivalency diploma (GED) and $11 \%$ of young adults had completed some college. The majority of participants came from families with low parent/caretaker income; $34 \%$ reported growing up on welfare. The mean family income for these youth growing up was approximately $\$ 10,000$ to $\$ 15,000$. Only $7 \%$ of the sample indicated that their parent/caretaker income was $\$ 50,000$ or above. Finally, the total number of times youth had run away from home ranged from 1 to 51 times with a mean of five runs. There was no significant difference between those who had previously run but were currently housed at the time of the interview and those who were currently homeless at the time of the interview.

\section{Measures}

Sexual abuse was measured using seven items. Youth were asked how often an adult, an individual at least five years older than them, had done the following things to them before they were on their own and while they were under the age of 18: (a) asked you to do something sexual; (b) had you watch them do something sexual; (c) had you do something sexual to yourself; (d) had you touch them sexually; (e) had you show your "private parts" in person or for a camera; (f) touched you sexually on your butt, thigh, breast, or genitals; and (g) put or tried to put anything or any part of their body into you sexually when you did not want them to. Each item was dichotomized $(0=$ never and $1=$ at least once $)$ and the seven items were then summed. Because the variable was highly skewed, the resulting item was dichotomized into $0=$ no sexual abuse and 1 = experienced at least one form of sexual abuse at least once.

Neglect was composed of five items from a supplementary scale within the CTSPCCA (Straus, Hamby, Finkelhor, Moore, \& Runyan, 1998). These items asked respondents how many times their caretaker left them home alone when someone should have been with them, was not able to show them that they were loved, was not able to give them the food they needed, did not take them to the doctor/hospital when they needed to go, and was drunk or high on drugs and could not take care of them. Individual items were first dichotomized and then summed so that a higher score indicated more types of neglect. The alpha reliability for this scale was .76.

Depressive symptoms consisted of 10 items from a short form of the Center for Epidemiological Studies Depression scale (CES-D) (Radloff, 1977). Interviewers asked re- 
spondents how many days in the previous week they experienced depressive symptoms such as being bothered by things that do not usually bother them, having trouble keeping their mind on things, feeling low in energy, feeling restless, and if they felt lonely. Responses ranged from $0=$ rarely or none of the time (less than one day) to 3 $=$ most or all of the time (5-7 days). Certain items were reverse coded so that higher scores indicated more depressive symptoms. The items were summed and the resulting scale was then dichotomized using the cutoff score of 10 (Anderson, Malmgren, Carter, \& Patrick, 1994; Boey, 1999). Scoring above this cutoff indicated the existence of depressive symptoms. The alpha reliability was .80 .

Traded sex was a combination of several items that asked respondents if they had ever traded sex in return for something such as money, a place to stay, or drugs. Also, an open-ended question asked youth what kinds of things they had done to get by on the streets when they had few other options. Those who indicated that they had engaged in trading sex for any type of item were also included in this count. The final variable was dichotomized into $0=$ never traded sex, and $1=$ traded sex at least once.

Prostitution was a composite variable made up of four items. First, respondents were asked how often they had engaged in prostitution. Second, interviewers asked respondents how much time they spent on the street "turning tricks." Third, in the same open-ended question mentioned previously, some youth reported having engaged in prostitution when they had few other options. Finally, another open-ended question asked youth what kind of work they did, and some youth reported that prostitution was their source of employment. These items were combined to create a single-item dichotomous measure of prostitution: $0=$ youth had never engaged in prostitution according to all four variables, and $1=$ youth had engaged in prostitution according to at least one of the four variables.

Friends traded sex was a single item that asked young people if any of their friends had ever traded sex for food, money, and/or shelter. Responses included $0=$ no, and $1=$ yes.

Sexual victimization consisted of four items that focused on the frequency with which respondents had unwanted sexual experiences (adapted from Whitbeck \& Simons, 1990). Items included having been asked to touch someone sexually when they did not want to, having been touched sexually when they did not want to be, having been forced to do something sexual, and having been sexually assaulted and/or raped. Responses ranged from $0=$ never to $3=$ many times. Each of the individual items were dichotomized and then summed, with a higher score indicating that the youth had experienced a greater number of different types of sexual victimization. Cronbach's alpha for the sexual victimization items was .83 .

Sexual orientation was assessed with a question in which the youth identified themselves as straight or heterosexual, gay or lesbian, bisexual, transgender, or confused/ unsure. The variable was coded so that any individual listing a nonheterosexual sexual identity was coded as 0 and youth who indicated a heterosexual orientation were coded as 1 . No one self-identified as transgender. Although some studies group youth who identify as confused/unsure into GLB, to ensure a conservative estimate, youth who marked confused/unsure were coded into missing $(n=4)$ for the current study.

Gender was coded 0 for males and 1 for females. All models controlled for gender.

\section{RESULTS}

The bivariate correlations for all study variables are presented in Table 1. Results revealed that sexual victimization was positively associated with being sexually abused $(r=.32 ; p \leq .01)$, higher levels of neglect $(r=.28 ; p \leq .01)$, being depressed $(r=.30 ; p \leq$ 
$.01)$, having traded sex $(r=.29 ; p \leq .01)$, having prostituted $(r=.28 ; p \leq .01)$, and having friends who have traded $\operatorname{sex}(r=.40 ; p \leq .01)$. Females $(r=.34 ; p \leq .01)$ and sexual minority youth $(r=-.34 ; p \leq .01)$ experienced more sexual victimization compared to males and heterosexual youth, respectively. ${ }^{1}$

Table 2 presents the means difference between heterosexual and GLB youth. Results revealed that GLB youth experienced significantly more sexual victimization $(t=4.53$; $p$ $\leq .001)$ and higher levels of neglect $(t=1.83 ; p<.10)$ and were more likely to have been sexually abused $\left(\chi^{2}=7.65 ; p \leq .01\right)$ and depressed $\left(\chi^{2}=4.83 ; p \leq .05\right)$. Also, sexual mi-

Table 1. Correlations Between All Study Variables $(N=158)$

\begin{tabular}{|c|c|c|c|c|c|c|c|c|c|}
\hline & 1 & 2 & 3 & 4 & 5 & 6 & 7 & 8 & 9 \\
\hline $\begin{array}{l}1 \text { Sexual } \\
\text { victimization } \\
2 \text { Gender } \\
(1=\text { female })\end{array}$ & $.34^{\star *}$ & - & & & & & & & \\
\hline $\begin{array}{c}3 \text { Sexual orientation } \\
(1=\text { heterosexual })\end{array}$ & $-.34^{* *}$ & $-.16^{*}$ & - & & & & & & \\
\hline 4 Sexual abuse & $.32 * *$ & $.22 * *$ & $-.22^{* *}$ & - & & & & & \\
\hline $\begin{array}{l}5 \text { Neglect } \\
6 \text { Depressive }\end{array}$ & $.28^{* *}$ & .09 & -.15 & $.26^{* *}$ & -- & & & & \\
\hline symptoms & $.30^{* *}$ & .02 & $-.18^{*}$ & .14 & $.23^{* *}$ & - & & & \\
\hline 7 Ever traded sex & $.29^{* *}$ & .12 & $-.19 *$ & $.19^{*}$ & .09 & $.18^{*}$ & - & & \\
\hline $\begin{array}{l}8 \text { Ever prostituted } \\
9 \text { Friends ever }\end{array}$ & $.28^{* *}$ & .15 & -.15 & .11 & .13 & .09 & $.35^{* *}$ & - & \\
\hline traded sex & $.40^{* *}$ & .12 & $-.31^{* *}$ & $.27^{* *}$ & $.20^{*}$ & $.16^{*}$ & $.35^{* *}$ & .12 & - \\
\hline Mean & .85 & .38 & .83 & .46 & 2.11 & .67 & .15 & .04 & .44 \\
\hline SD & 1.34 & .49 & .38 & .50 & 1.73 & .47 & .35 & .21 & .50 \\
\hline
\end{tabular}

${ }^{*} p \leq .05$ (two-tailed test). ${ }^{* *} p \leq .01$.

Table 2. Descriptive Statistics of All Study Variables by Sexual Orientation

\begin{tabular}{|c|c|c|c|c|c|}
\hline & \multicolumn{2}{|c|}{$\begin{array}{l}\text { Heterosexual } \\
\quad(n=131)\end{array}$} & \multicolumn{2}{|c|}{$\begin{array}{l}\text { GLB } \\
(n=27)\end{array}$} & \multirow{2}{*}{$\begin{array}{l}\text { Means } \\
\text { Difference }\end{array}$} \\
\hline & Mean & $S D$ & Mean & $S D$ & \\
\hline Sexual victimization (0-4) & .64 & 1.14 & 1.85 & 1.77 & $4.53^{* * *}$ \\
\hline Sexual abuse $(0-1)$ & .41 & .49 & .70 & .47 & $7.65^{* *}$ \\
\hline Neglect (0-5) & 2.00 & 1.70 & 2.67 & 1.84 & $1.83^{* * * *}$ \\
\hline Depressive symptoms $(0-1)$ & .63 & .48 & .85 & .36 & $4.83^{*}$ \\
\hline Ever traded sex $(0-1)$ & .11 & .32 & .30 & .47 & $5.95^{*}$ \\
\hline Ever prostituted (0-1) & .03 & .17 & .11 & .32 & $3.43^{* * * *}$ \\
\hline Friends ever traded sex $(0-1)$ & .37 & .49 & .78 & .42 & $14.79^{* * *}$ \\
\hline
\end{tabular}

${ }^{\mathrm{a}}$ Difference between heterosexual and GLB means ( $t$ test for continuous variables and $\chi^{2}$ for dichotomous variables).

${ }^{*} p \leq .05 .{ }^{* *} p \leq .01 .{ }^{* * *} p \leq .001 .{ }^{* * * *} p<.10$. 
nority youth were significantly more likely to have traded $\operatorname{sex}\left(\chi^{2}=5.95 ; p \leq .05\right)$, prostituted $\left(\chi^{2}=3.43 ; p<.10\right)$, and to have friends who traded sex $\left(\chi^{2}=14.79 ; p \leq .001\right)$.

For the multivariate analyses, ordinary least squares regression was used to predict sexual victimization among study participants (Table 3). To see the individual effect of each group of variables (e.g., maltreatment, mental health) on sexual victimization, the variables were entered sequentially in six separate blocks. ${ }^{2}$ This procedure also follows a temporal order; maltreatment occurred before youth running away, whereas the risky behavior occurred after youth have left home. Model 1, which included the demographic variables, revealed that females $(\beta=.29 ; p \leq .01)$ and sexual minority youth $(\beta=-.29 ; p \leq .01)$ experienced significantly more sexual victimization compared to males and heterosexual youth, respectively. These two variables alone explained $19 \%$ of the variance in the outcome variable.

Model 2, which added in the maltreatment variables, revealed that both sexual abuse $(\beta=.17 ; p \leq .05)$ and neglect $(\beta=.18 ; p \leq .01)$ were associated with sexual victimization. That is, those who experienced sexual abuse and those who had higher levels of neglect experienced more sexual victimization since being on the street. Females $(\beta=.25 ; p \leq .01)$ and sexual minority youth $(\beta=-.24 ; p \leq .01)$ both experienced more sexual victimization. The explained variance for Model 2 was $25 \%$.

The results for Model 3 revealed that depressed youth experienced more sexual victimization $(\beta=.21 ; p \leq .01)$. As in the previous model, both maltreatment variables (i.e., sexual abuse and neglect) remained significantly associated with sexual victimization as did being female and a sexual minority. Model 3 explained $29 \%$ of the variance in sexual victimization.

In Model 4 , results revealed that trading sex $(\beta=.15 ; p \leq .05)$ was associated with higher levels of sexual victimization. Similar to Model 3, depressive symptoms, maltreatment, being female, and a sexual minority were all significantly related to higher levels of sexual victimization. Model 4 explained 31\% of the variance. In Model 5, having ever prostituted $(\beta=.13 ; p<.10)$ was marginally associated with higher levels of sexual victimization. Trading sex, however, was reduced to nonsignificance. All of the other variables remained significant correlates. Model 5 explained 32\% of the variance in sexual victimization.

Finally, Model 6 added the friends trading sex variable, which was significant $(\beta=$ $.21 ; p \leq .01$ ). That is, youths whose friends have traded sex were more likely to report higher rates of sexual victimization. Prostitution, depressive symptoms, gender, and sexual orientation all remained significant; however, the maltreatment variables were reduced to nonsignificance. This final model explained $35 \%$ of the variance in homeless young adults' sexual victimization.

Because rates of sexual victimization were expected to differ by sexual orientation, a series of interactions were examined to test the extent to which the effect of sexual orientation on sexual victimization was moderated by maltreatment, depressive symptoms, risky sexual behavior, and friends trading sex. Although all possible combinations of the variables were included as interactions to predict sexual victimization, only those that were significant at the .05 level or below were included in this discussion. This included a total of two interactions.

Significant Interactions. The interaction term trading sex $\times$ sexual orientation $(\beta=-$ $.26 ; p \leq .05$; see Figure 1 ) indicated that sexual minority youth who had ever traded sex experienced higher levels of sexual victimization compared to heterosexual youth who traded sex. In Figure 2, the interaction term friends traded sex $\times$ sexual orientation revealed that sexual minority youth who had friends who traded sex experienced higher rates of sexual victimization compared to both youth without friends who traded sex and heterosexual youth with friends who traded $\operatorname{sex}(\beta=-.42 ; p \leq .05$; see Figure 2$)$. 


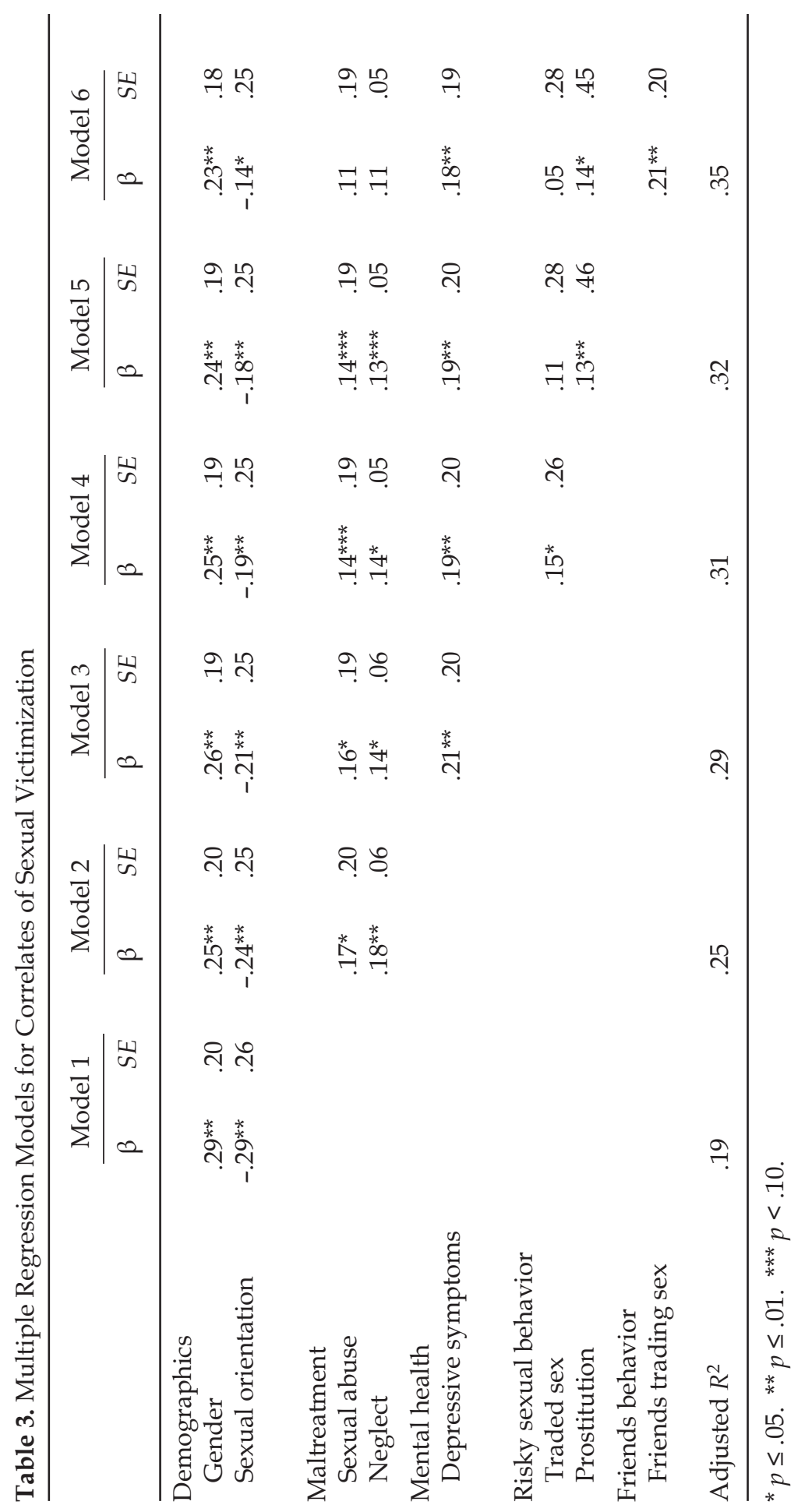




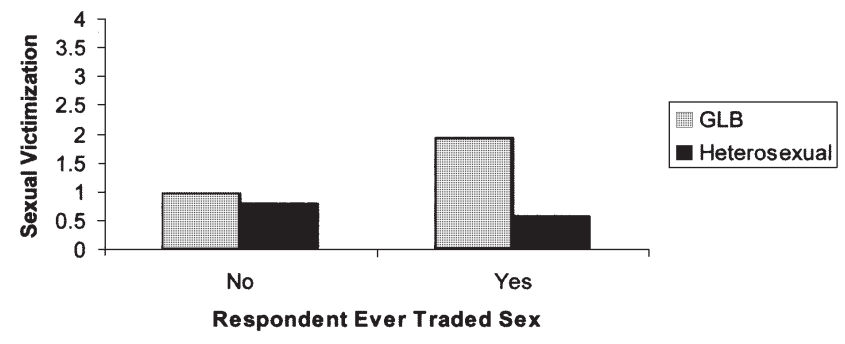

Figure 1. Ever traded sex by sexuality on sexual victimization.

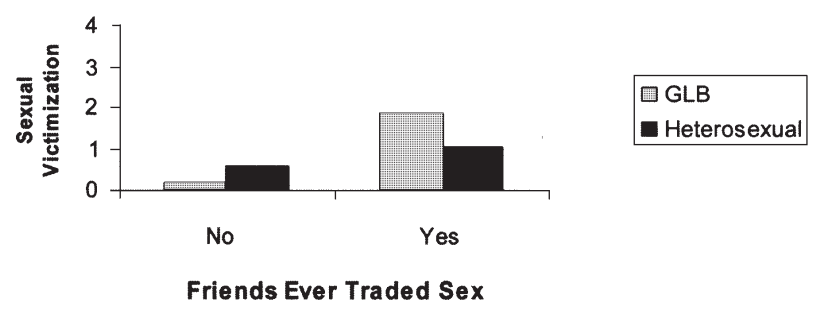

Figure 2. Friends traded sex by sexuality on sexual victimization.

Finally, to examine whether the effect of sexual abuse, neglect, and depressive symptoms on sexual victimization was indirect, mediation effects were tested based on Baron and Kenny's (1986) method. First, the effect of sexual abuse on sexual victimization was examined to see if this relationship was mediated by depressive symptoms, trading sex, prostitution, and friends trading sex. Results indicated that partial mediation was demonstrated by the reduction in betas for the effect of sexual abuse on sexual victimization when trading sex was included in the model (from $\beta=.324$; $p \leq .001$ to $\beta=.278 ; p \leq .001)$, which was statistically significant $(z=1.984, p \leq .05)$ using Sobel's (1988) formula. The effect of sexual abuse on sexual victimization was also partially mediated by friends trading sex as demonstrated by the statistically significant reduction in betas (from $\beta=.324 ; p \leq, 001$ to $\beta=.233 ; p \leq .01 ; z=2.298, p \leq .05$ ). Although there was a reduction in the effect of sexual abuse on sexual victimization when depressive symptoms was included in the model (from $\beta=.324 ; p \leq .001$ to $\beta=$ $.288 ; p \leq .001)$, this reduction was not statistically significant $(z=1.557, p=.12)$. There was no support for the mediation of the effects of sexual abuse on sexual victimization via prostitution.

Next, the effect of neglect on sexual victimization was examined to see if this relationship was mediated by depressive symptoms, trading sex, prostitution, and friends trading sex. Support was demonstrated for the partial mediation of the effect of neglect on sexual victimization via friends trading sex by a significant reduction in the betas (from $\beta=.284 ; p \leq .001$ to $\beta=.214 ; p \leq .01 ; z=1.886, p \leq .10$ ). Support was also demonstrated for the partial mediation of the effect of neglect on sexual victimization via depressive symptoms by a significant reduction in betas (from $\beta=.284 ; p \leq .001$ to $\beta=.227 ; p \leq .01 ; z=2.029, p=.05$ ). No support was found for mediation of the effects of neglect on sexual victimization via trading sex or prostitution. 
Finally, the effect of depressive symptoms on sexual victimization was examined to see whether this relationship was mediated by trading sex, prostitution, and friends trading sex. Results indicated support for significant partial mediations of the effects of depressive symptoms on sexual victimization through trading sex (reduction in betas from $\beta=.303 ; p \leq .001$ to $\beta=.261 ; p \leq .001 ; z=1.778, p \leq .10)$ and friends trading sex (reduction in betas from $\beta=.303 ; p \leq .001$ to $\beta=.245 ; p \leq .001 ; z=1.750, p \leq .10$ ). There was no support found for mediation of the effects of depressive symptoms on sexual victimization via prostitution.

\section{DISCUSSION}

This article set out to examine the association between early sexual abuse, neglect, depressive symptoms, risky sexual behavior, and friends trading sex with sexual victimization among homeless heterosexual males and females and homeless gay, lesbian, and bisexual (GLB) young adults. This study also examined the extent to which the effect of sexual orientation on sexual victimization was moderated by maltreatment, depressive symptoms, risky sexual behavior, and friends trading sex and the extent to which sexual abuse, neglect, and depressive symptoms on sexual victimization were mediated by other risk factors. Consistent with what was hypothesized, GLB young adults experience more sexual victimization than heterosexual young adults even after controlling for other risk factors, which is consistent with previous research (Whitbeck et al., 2004). It is possible that as a result of their lack of family support (D'Augelli, 1998) and the fact that sexual minority youth are more likely to run away or be expelled from home than their heterosexual peers (Cochran et al., 2002; Martin \& Hetrick, 1988; Remafedi, 1987; Savin-Williams, 1994), they may be less likely to return home and hence have fewer resources and support available. As a result, they may be more likely to trade sex to support themselves compared to their heterosexual peers, which is consistent with previous research (Clatts \& Davis, 1999; Kipke et al., 1997a; Moon et al., 2000; Whitbeck et al., 2004). It is likely that trading sex puts these young people in dangerous and vulnerable situations with little protection from violent customers and others who may exploit them (Tyler et al., 2004; Weisberg, 1985). As a result, trading sex increases their risk for sexual victimization (Tyler et al., 2001a).

It is also possible that the higher rate of victimization among GLB youth is due to bias-related crime because such crimes occur in public settings and are perpetrated by strangers (Herek et al., 2002), exactly the places and people that homeless GLB youth are likely to be surrounded by. Bias-related crimes may increase their chances for victimization above and beyond heterosexual homeless youth.

Although sexual abuse is no longer associated with sexual victimization when controlling for all of the other risk factors, support is found for partial mediation of the effects of sexual abuse on sexual victimization through trading sex and friends trading sex, which means that sexual abuse remains influential in the prediction of sexual victimization because it works indirectly through other more proximal factors (e.g., risky sexual behavior). This is consistent with previous research on homeless youth that finds support for indirect effects between child sexual abuse and later sexual victimization (Tyler et al., 2000; Tyler et al., 2001a). Much of the research on non-homeless populations also supports the link between childhood abuse and an increased risk for adult victimization ( $c f$. Gidycz, Coble, Latham, \& Layman, 1993; Jankowski, Leitenberg, Henning, \& Coffey, 2002; Siegel \& Williams, 2003). 
Neglect is also a risk factor for sexual victimization, which is consistent with previous research on homeless youth (Whitbeck et al., 2004). It is possible that parents who are unable to take care of their children and who are unable to tell them that they are loved may result in the child looking for affection elsewhere. This may result in young girls, for example, having older boyfriends, which may increase their risk for becoming a victim. Neglected children may also look for affection and love in casual relationships, which may also lead to increased sexual victimization. Although neglect drops to nonsignificance in the final model, support is found for partial mediation of the effect of neglect on sexual victimization through depressive symptoms and friends trading sex. Youth who experience neglect become depressed and may feel isolated and, as a result, gravitate toward high-risk activities (Finkelhor \& Browne, 1985; Whitbeck et al., 2004), including associating with peers who trade sex, both of which are risk factors for sexual victimization. In the current study, sexual minority youth experienced more neglect compared to their heterosexual counterparts, which is consistent with previous research (Whitbeck et al., 2004). One possible explanation for the higher rate of neglect among GLB youth may be due to the isolation, stigmatization, and discrimination that they experience at the hands of their parents and friends specifically because of their sexual orientation (D'Augelli, 1998; Kruks, 1991). This lack of care and concern is also evident when parents argue with youth over their sexual orientation, and these same youth leave home as a result of this (Cochran et al., 2002).

In the current study, depressed youth are more likely to experience sexual victimization, a finding that is consistent with the literature (Whitbeck et al., 2000). Depressed youth may have lower self-esteem and a negative self-image and thus may appear more vulnerable to potential offenders and may increase their risk for victimization (Tyler et al., 2000). Support is also found for partial mediation for the effects of depressive symptoms on sexual victimization through trading sex and friends trading sex. Depressed youth may feel isolated and gravitate toward high-risk activities (Finkelhor \& Browne, 1985). This may be particularly relevant for homeless youth who are out on the streets with limited resources and may resort to risky sexual behaviors to survive. These activities potentially increase the risk for victimization. GLB youth in the current study are more depressed than their heterosexual peers, which is consistent with the literature (Cochran et al., 2002; Whitbeck et al., 2004). Although one would expect high rates of depression among homeless youth in general, GLB youth are likely to face double jeopardy because not only are they experiencing the daily struggles associated with being homeless, but they also experience discrimination owing to their sexual orientation (Cochran et al., 2002).

Prostitution is a significant correlate of sexual victimization in the current study. It is likely that prostitution increases young people's visibility and exposure to potential offenders (Cohen et al., 1981) and puts them in dangerous and vulnerable situations with little protection from violent customers and others who may try to exploit them (Tyler et al., 2004; Weisberg, 1985) and, as a result, increases homeless youths' risk for sexual victimization.

Although trading sex was a significant correlate of sexual victimization, it dropped to nonsignificance in the final model. The significant interaction between sexual orientation and trading sex, however, demonstrates that trading sex is more of a risk factor for sexual victimization for GLB youth compared to their heterosexual peers. One possible explanation may be because GLB youth are more likely to run away or be expelled from home (Cochran et al., 2002; Remafedi, 1987; Savin-Williams, 1994) and hence have fewer resources. As a result, they are more likely to trade sex to support themselves. Another explanation is that because GLB youth trade sex more often, they have greater exposure 
to potential offenders, which increases their risk for more sexual victimization. Finally, the higher rate of sexual victimization may be bias related owing to their sexual orientation (Herek et al., 2002; Hershberger \& D'Augelli, 1995; Huebner et al., 2004; Willis, 2004). Bias-related crime may be especially prevalent because such crimes occur in public settings and are perpetrated by strangers (Herek et al., 2002); GLB youth who trade sex are likely to be found in such places surrounded by strangers.

In the current study, having friends who trade sex is also a risk factor for sexual victimization among homeless young adults. Because homeless youth are often coerced, manipulated, or forced to trade sex, which is often instigated by a friend or sexual partner who also trades sex (Hagan \& McCarthy, 1997; Tyler \& Johnson, 2006), youth who have friends who trade sex may be at greater risk for becoming personally involved, and trading sex or engaging in prostitution increases the risk for sexual victimization (Tyler et al., 2001a; Tyler et al., 2004). Also, because many homeless youth report hanging out with friends as their main activity (Yates et al., 1988) and that street peers provide guidance and instruction that aid youth in surviving on the street (Hagan \& McCarthy, 1997; Kipke et al., 1997b), it is not surprising that homeless youth are strongly influenced by the behaviors of such youth, which will likely affect homeless youths' decision to engage in similar activities, including trading sex (Ennett, Bailey, \& Federman, 1999). Further, the street environment, which is characterized by limited resources and exposure to deviant youth, may make it easier for these young people to become involved in trading sex. One caveat with crosssectional data, however, is that it cannot be determined if youth in the current study traded sex first or whether they learned this survival strategy from their friends. Either way, associating with friends who trade sex heightens the likelihood for sexual victimization among current study participants.

The current study also finds that not only are GLB youth more likely to have friends who trade sex compared to their heterosexual peers, but the significant interaction of sexual orientation by friends trading sex indicates that they are more likely to be at risk for sexual victimization because of this. Because GLB homeless youth are more likely to trade sex, as the research suggests (Clatts \& Davis, 1999; Kipke et al., 1997a; Kipke et al., 1995; Moon et al., 2000; Whitbeck et al., 2004), it seems plausible that they are likely to have more friends who trade sex, thus making them more vulnerable. Once again, the causal order in terms of who traded sex first (i.e., respondents or their friends) is unclear. The interaction only demonstrates that GLB have more friends who trade sex and that this is a greater risk factor for them compared to their heterosexual counterparts. Some limitations should be kept in mind when interpreting these results. First, the findings are based on cross-sectional data. Although many of these variables are correlated, cause and effect cannot be assumed. Based on the sexual abuse literature, however, the temporal ordering of abuse and neglect before depression is plausible. Although it is likely that risky sexual behaviors occur after youth have left home, their order of influence is less clear (i.e., friends trading sex and respondents trading sex). Second, youth are reporting on sensitive topics, and it is possible that some of them were unwilling to disclose their participation in some of the activities. Consequently, results may be underestimates of the actual occurrences of high-risk behaviors. Finally, youth are asked to report on the behavior of their friends (i.e., friends trading sex), and it is possible that youth are overreporting or underreporting this behavior.

Notwithstanding these concerns, these findings build on existing data and shed important light on risk factors for sexual victimization among a sample of sexual minority and heterosexual homeless young adults, an understudied population on which little research exists. In addition, the findings demonstrate that the effect of sexual orienta- 
tion on sexual victimization varies by different risk factors and that numerous indirect effects are significant. Finally, these findings have important implications for those who work with homeless youth in general and GLB homeless youth in particular.

\section{Policy Implications}

In general, the findings from the current study suggest that early underlying problems including sexual abuse, neglect, and depressive symptoms lead to youths' involvement in risky behaviors, which in turn increase the risk for sexual victimization. The current study also finds that GLB youth are especially vulnerable to sexual victimization. Stressors such as discrimination, isolation, stigmatization, and being unable to return to their home may account for their higher rate of sexual victimization compared to their heterosexual counterparts. Also, bias-related crimes that are due specifically to sexual orientation may also account for their greater risk. All of this suggests that interventions need to take into account the specific stressors that these young people are experiencing. Shelters and agencies need to advertise, through posters or flyers for example, that sexual minority youth are welcome and are encouraged to seek out services. Gay and lesbian staff members who are open about their sexual orientation may also increase the likelihood that this vulnerable group will seek services.

Another policy implication is that abuse and neglect histories may continue to impact the mental health and current relationships of these young people for quite some time and, if left untreated, may have long-term effects. As such, case workers and service providers will have to work with these young adults to help change their negative self-image. Numerous negative health outcomes are associated with trading sex, prostitution, and being a victim of sexual assault including sexually transmitted diseases, HIV infection, and emotional trauma. Again, because GLB youth tend to have higher rates of trading sex, victimization, and depression, they are especially vulnerable and need to be offered services that are sensitive to their sexual orientation and the kinds of barriers that they face.

Third, the young adults in the current study are at a critical transition period when work patterns are typically established and intimate relations are formed. Failure to establish oneself as a young adult may have long-term repercussions including becoming part of a growing older homeless population. Services that provide counseling, job training, and employment opportunities are needed to reduce homeless young adults' reliance on risky sexual behaviors. These services may also work toward permanently removing young people from the streets. Because GLB youth are likely to be overrepresented in homeless and runaway populations, however, interventions are needed that target the specific needs of this group, and such services need to be made widely available. Further, by alerting GLB youth that they have a safe place to go and agencies are willing and able to provide services may help to reduce the risk of victimization among this vulnerable group.

\section{NOTES}

1. Although some of the variables in the analysis measure similar constructs, we do not have a problem with multicollinearity (Tabachnick \& Fidell, 2001); the strongest correlation was .40.

2. Collinearity was not a problem in any of the models because variance inflation factors were all well below 5 (Menard, 1995).

3. Although the trading sex variable was entered into the regression model before the friends trading sex variable, it is not assumed that the first variable "causes" the second variable or vice versa, only that they are related. 


\section{REFERENCES}

Anderson, E. M., Malmgren, J. A., Carter, W. B., \& Patrick, D. L. (1994). Screening for depression in well older adults: Evaluation of a short form of the CESD-D. American Journal of Preventative Medicine, 10, 77-84.

Baron, S. W. (1997). Risky lifestyles and the link between offending and victimization. Studies of Crime and Crime Prevention, 6, 53-71.

Baron, S. W. (2003). Street youth violence and victimization. Trauma, Violence, \& Abuse, 4, 22-44.

Baron, R. M., \& Kenny, D. A. (1986). The moderator-mediator variable distinction in social psychological research: Conceptual, strategic, and statistical considerations. Journal of Personality and Social Psychology, 51, 1172-1182.

Boey, K. W. (1999). Cross-validation of a short form of the CES-D in Chinese elderly. International Journal of Geriatric Psychiatry, 14, 608-617.

Clatts, M. C., \& Davis, W. R. (1999). A demographic and behavioral profile of homeless youth in New York City: Implications for AIDS outreach and prevention. Medical Anthropology Quarterly, 13, 365-374.

Cochran, B. N., Stewart, A. J., Ginzler, J. A., \& Cauce, A.M. (2002). Challenges faced by homeless sexual minorities: Comparison of gay, lesbian, bisexual, and transgender homeless adolescents with their heterosexual counterparts. American Journal of Public Health, 92, 773-777.

Cohen, L. E., Kluegel, J. R., \& Land, K. C. (1981). Social inequality and predatory criminal victimization: An exposition and test of a formal theory. American Sociological Review, 46, 505-524.

D'Augelli, A. R. (1998). Developmental implications of victimization of lesbian, gay, and bisexual youths. In G. M. Herek (Ed.), Stigma and sexual orientation: Understanding prejudice against lesbians, gay men, and bisexuals (pp. 187-210). Thousand Oaks, CA: Sage Publications, Inc.

D' Augelli, A. R., Hershberger, S. L., \& Pilkington, N. W. (1998). Lesbian, gay, and bisexual youth and their families: Disclosure of sexual orientation and its consequences. American Journal of Orthopsychiatry, 68, 361-371.

Ennett, S. T., Bailey, S. L., \& Federman, E. B. (1999). Social network characteristics associated with risky behaviors among runaway and homeless youth. Journal of Health and Social Behavior, 40, 63-78.

Finkelhor, D., \& Browne, A. (1985). The traumatic impact of child sexual abuse: A conceptualization. Journal of Orthopsychiatry, 55, 530-541.

Gidycz, C. A., Coble, C. N., Latham, L., \& Layman, M. J. (1993). Sexual assault experience in adulthood and prior victimization experiences. Psychology of Women Quarterly, 17, 151-168.

Hagan, J., \& McCarthy, B. (1997). Mean streets: Youth crime and homelessness. New York: Cambridge University Press.

Herek, G. M., Cogan, J. C., \& Gillis, J. R. (2002). Victim experiences in hate crimes based on sexual orientation. Journal of Social Issues, 58, 319-339.

Hershberger, S. L., \& D'Augelli, A. R. (1995). The impact of victimization on the mental health and suicidality of lesbian, gay, and bisexual youths. Developmental Psychology, 31, 65-74.

Huebner, D. M., Rebchook, G. M., \& Kegeles, S. M. (2004). Experiences of harassment, discrimination, and physical violence among young gay and bisexual men. American Journal of Public Health, 94, 1200-1203.

Jankowski, M. K., Leitenberg, H., Henning, K., \& Coffey, P. (2002). Parental caring as a possible buffer against sexual revictimization in young adult survivors of child sexual abuse. Journal of Traumatic Stress, 15, 235-244.

Kipke, M. D., Montgomery, S. B., Simon, T. R., Unger, J. B., \& Johnson, C. J. (1997a). Homeless youth: Drug use patterns and HIV risk profiles according to peer group affiliation. AIDS and Behavior, 1, 247-259.

Kipke, M. D., O'Connor, S., Palmer, R., \& MacKenzie, R. G. (1995). Street youth in Los Angeles: Profile of a group at high risk for HIV. Archives of Pediatric and Adolescent Medicine, 149, 513-519. 
Kipke, M. D., Unger, J. B., O'Connor, S., Palmer, R. F., \& LaFrance, S. R. (1997b). Street youth, their peer group affiliation and differences according to residential status, subsistence patterns, and use of services. Adolescence, 32, 655-669.

Kruks, G. (1991). Gay and lesbian homeless/street youth: Special issues and concerns. Journal of Adolescent Health, 12, 515-518.

Martin, A. D., \& Hetrick, E. S. (1988). The stigmatization of the gay and lesbian adolescent. Journal of Homosexuality, 15, 163-183.

Menard, S. (1995). Applied logistic regression analysis (Sage University Paper series on quantitative applications in the social sciences, 106). Thousand Oaks, CA: Sage.

Moon, M. W., McFarland, W., Kellogg, T., Baxter, M., Katz, M. H., MacKellar, D., \& Valleroy, L. A. (2000). HIV risk behavior of runaway youth in San Francisco: Age of onset and relation to sexual orientation. Youth \& Society, 32, 184-201.

Morrow, K. B., \& Sorell, G. T. (1989). Factors affecting self-esteem, depression, and negative behaviors in sexually abused female adolescents. Journal of Marriage and the Family, 51, 677-686.

Noell, J. W., \& Ochs, L. M. (2001). Relationship of sexual orientation to substance use, suicidal ideation, suicide attempts, and other factors in a population of homeless adolescents. Journal of Adolescent Health, 29, 31-36.

Overall, C. (1992). What's wrong with prostitution? Evaluating sex work. Signs, 17, 705-724.

Pilkington, N. W., \& D'Augelli, A. R. (1995). Victimization of lesbian, gay, and bisexual youth in community settings. Journal of Community Psychology, 23, 34-56.

Radloff, L. S. (1977). The CES-D Scale: A self-report depression scale for research in the general population. Applied Psychological Measurement, 1, 385-401.

Remafedi, G. (1987). Adolescent homosexuality: Psychosocial and medical implications. Pediatrics, 79, 331-337.

Rew, L., Whittaker, T. A,, Taylor-Seehafer, M. A,, \& Smith, L. R. (2005). Sexual health risks and protective resources in gay, lesbian, and bisexual, and heterosexual homeless youth. Journal for Specialists in Pediatric Nursing, 10, 11-19.

Ryan, K. D., Kilmer, R. P., Cauce, A. M., Watanabe, H., \& Hoyt, D. R. (2000). Psychological consequences of child maltreatment in homeless adolescents: Untangling the unique effects of maltreatment and family environment. Child Abuse \& Neglect, 24, 333-352.

Savin-Williams, R. C. (1994). Verbal and physical abuse as stressors in the lives of lesbian, gay male, and bisexual youths: Associations with school problems, running away, substance abuse, prostitution, and suicide. Journal of Consulting and Clinical Psychology, 62, 261-269.

Siegel, J. A., \& Williams, L. M. (2003). Risk factors for sexual victimization of women. Violence Against Women, 9, 902-930.

Silbert, M. H., \& Pines, A. M. (1982). Entrance into prostitution. Youth $\mathcal{E}$ Society, 13, 471-500.

Simons, R. L., \& Whitbeck, L. B. (1991). Sexual abuse as a precursor to prostitution and victimization among adolescent and adult homeless women. Journal of Family Issues, 12, 361-379.

Sobel, M. E. (1988). Direct and indirect effect in linear structural equation models. In J. S. Long (Ed.), Common problems/proper solutions: Avoiding error in quantitative research (pp. 46-64). Beverly Hills, CA: Sage.

Stiffman, A. R. (1989). Physical and sexual abuse in runaway youth. Child Abuse \& Neglect, 13, 417-426.

Straus, M. A., Hamby, S. L., Finkelhor, D., Moore, D. W., \& Runyan, D. (1998). Identification of child maltreatment with the parent-child conflict tactics scales: Development and psychometric data for a national sample of American parents. Child Abuse \& Neglect, 22, 249-270.

Tabachnick, B. G., \& Fidell, L. S. (2001). Using multivariate statistics (4th ed.). Needham Heights, MA: Allyn \& Bacon.

Tyler, K. A. (2002). Social and emotional outcomes of childhood sexual abuse: A review of recent research. Aggression and Violent Behavior, 7, 567-589. 
Tyler, K. A., \& Cauce, A. M. (2002). Perpetrators of early physical and sexual abuse among homeless and runaway adolescents. Child Abuse \& Neglect, 26, 1261-1274.

Tyler, K. A,, Hoyt, D. R., \& Whitbeck, L. B. (2000). The effects of early sexual abuse on later sexual victimization among female homeless and runaway youth. Journal of Interpersonal Violence, 15, 235-250.

Tyler, K. A., Hoyt, D. R., Whitbeck, L. B., \& Cauce, A. M. (2001a). The impact of childhood sexual abuse on later sexual victimization among runaway youth. Journal of Research on Adolescence, 11, 151-176.

Tyler, K. A., Hoyt, D. R., Whitbeck, L. B., \& Cauce, A. M. (2001b). The effects of a high-risk environment on the sexual victimization of homeless and runaway youth. Violence and Victims, $16,441-455$.

Tyler, K. A., \& Johnson, K. A. (2006). Trading sex: Voluntary or coerced? The experiences of homeless youth. Journal of Sex Research, 43, 208-216.

Tyler, K. A., Whitbeck, L. B., Hoyt, D. R., \& Cauce, A. M. (2004). Risk factors for sexual victimization among male and female homeless and runaway youth. Journal of Interpersonal Violence, 19, 503-520.

Weisberg, D. K. (1985). Children of the night: A study of adolescent prostitution. Lexington, MA: Lexington Books.

Whitbeck, L. B., Chen, X., Hoyt, D. R., Tyler, K. A., \&Johnson, K. D. (2004). Mental disorder, subsistence strategies, and victimization among gay, lesbian, and bisexual homeless and runaway adolescents. The Journal of Sex Research, 41, 329-342.

Whitbeck, L. B., \& Hoyt, D. R. (1999). Nowhere to grow: Homeless and runaway adolescents and their families. New York: Aldine de Gruyter.

Whitbeck, L. B., Hoyt, D. R., \& Bao, W. (2000). Depressive symptoms and co-occurring depressive symptoms, substance abuse, and conduct problems among runaway and homeless adolescents. Child Development, 71, 721-732.

Whitbeck, L. B., Hoyt, D. R., \& Yoder, K. A. (1999). A risk-amplification model of victimization and depressive symptoms among runaway and homeless adolescents. American Journal of Community Psychology, 27, 273-296.

Whitbeck, L. B., \& Simons, R. L. (1990). Life on the streets: The victimization of runaway and homeless adolescents. Youth \& Society, 22, 108-125.

Whitbeck, L. B., \& Simons, R. L. (1993). A comparison of adaptive strategies and patterns of victimization among homeless adolescents and adults. Violence and Victims, 8, 135-152.

Willis, D. G. (2004). Hate crimes against gay males: An overview. Issues in Mental Health Nursing, 25, 115-132.

Wright, J. D., Allen, T. L., \& Devine, J. A. (1995). Tracking nontraditional populations in longitudinal studies. Evaluation and Program Planning, 18, 267-277.

Yates, G. L., MacKenzie, R., Pennbridge, J., \& Cohen, E. (1988). A risk profile comparison of runaway and non-runaway youth. American Journal of Public Health, 78, 820-821.

\section{Acknowledgments}

This research was funded by the National Institute of Mental Health (K01 MH 064897), Dr. Kimberly A. Tyler, Principal Investigator.

Correspondence - Kimberly A. Tyler, PhD, University of Nebraska-Lincoln, Department of Sociology, 717 Oldfather Hall, Lincoln, NE 68588-0324. Email: kim@ktresearch.net 